\title{
Safety Climate in the Indian Manufacturing Industry - An Exploratory Study
}

\author{
Narayanappa Thimmarayappa Vijalapura \\ Deputy Director of Factories, Department of Factories, Boilers, Industrial Safety and Health, \\ Government of Karnataka, Bangalore, Karnataka, India
}

Tel: 91-96-2050-3318_E-mail: vijalapura_tvn@yahoo.com

\author{
,Swamy Devappa Renuka (Corresponding Author) \\ Dept. of Industrial Engineering and Management, \\ JSS Academy of Technical Education, Srinivasapura, Bangalore, India \\ Tel: 91-99-0000-5009Ｅ-mail: drswamydr@jssateb.ac.in \\ Pranesh Krishnamurthy \\ Dept. of Industrial Engineering and Management, \\ JSS Academy of Technical Education, Srinivasapura, Bangalore, India \\ Tel: 91-74-0690-7870Ｅ-mail: krishnamurthypranesh@gmail.com
}

Received: April 3, 2018 Accepted: April 15, 2018 Published: December 27, 2018

doi:10.5296/jss.v4i1.12943 URL: https://doi.org/10.5296/jss.v4i1.12943

\begin{abstract}
Research indicates safety climate is used to measure the safety of an organization. However, very few studies examine the status of safety climate in the manufacturing sector. This paper aims to explicate the status of safety climate in the Indian manufacturing sector. Four hundred fifty employees from 13 manufacturing industries in Karnataka were sampled. Perception data about the safety in their respective plants was collected using self-reporting questionnaires. The data was subjected to factor analysis, and Partial Least Squares regression was run to determine the nature of the relationships the constructs shared with Safety Climate.
\end{abstract}

Keywords: Safety Climate, Manufacturing Industry, India 


\section{Introduction}

Safety Climate is a term which captures the employees' perceptions about the safety management practices in their organization. Safety Climate was first defined in 1980 by Dov Zohar as the "molar summary of perceptions of employees regarding the safety in their organization" (Zohar, 1980). Safety climate was initially a part of safety management and safety culture; it has now evolved to focus solely on employee assessments of safety has become an extensive field of study. This makes it an important concept for organizations to understand and practice.

Safety Climate has been extensively researched in the years following its inception but, this research has not been towards understanding the theoretical underpinnings of safety from all possible viewpoints. Rather, the research effort has been focused on developing measuring instruments to quantify Safety Climate, which emphasize the employee's viewpoint (Zohar, 2010). Safety Climate research has progressed in four major paths, which are: a) measuring instruments to quantify Safety Climate b) theoretical models to explain the nature of Safety Climate c) the association between safety performance and Safety Climate are examined and d) links between Safety Climate and organizational climate are explored (Cooper et al., 2004).

Another issue in the field of Safety Climate research is relatively few sectors such as aviation, constructions, etc. are given extreme importance. Even though this has led to a better understanding of Safety Climate in those industries, a step-back reveals some industries such as manufacturing have not been studied as extensively because of the apparent lack of eye-opening events.

One sector that falls in the lesser studied category is the manufacturing industry. It is a well-known fact the importance of industries has sky-rocketed after industrialization and the manufacturing sector play an important role in this rapid increase in importance. This is important for India, which depends heavily on the manufacturing sector for economic support. However, the fact Safety Climate in the manufacturing sector in India has not been studied, as extensively as other sectors, more research effort needs to be directed in this direction. Measuring the safety climate provides safety of safety at a discrete point in time in an organization (Budworth, 1997). The safety climate measure provides a snapshot of safety culture as they reflect the workers' shared perception of how management and workers deal with safety on a day to day basis. The reason is that a rich safety culture and a matured safety climate are the most important factors for a achieving a safe workplace.

Hazardous and risk prone industries like aviation, nuclear energy and petrochemical sectors have been measuring safety climate from many years and using the results for the improvement of their safety standards. Measuring safety climate has various potential benefits which can be described at different levels (measuring safety culture, health.org.uk)

\section{i. Individual Team Members}

The safety climate surveys may increase the awareness of safety, safety-related conditions and behaviour at work place. 


\section{ii. Practice teams}

It acts as a diagnostic and educational tool at the practice team level, allowing and encouraging primary care teams to measure their safety climate and compare with regional aggregate, which helps in, prioritizing, designing and implementation of initiatives to build a stronger safety culture.

\section{iii. Organizational Level}

At the regional and organizational level, the perceptions of safety climate and related factors of different hazardous organizations and teams can be monitored, compared and influenced over time.

\section{iv. Secondary Care}

Emerging evidence from secondary care suggests that safety climate is associated with industrial worker outcomes. In Indian context, since Indian industries were using traditional safety management practices till recent times, the underlying factors and their effects on safety performance outcomes on all industries are yet to begin. The Indian industry has taken a risk to inherit the hazardous industries, passed through a rough terrain and seen a few disasters on its way like Bhopal gas tragedy, Vizag ONGC disaster, etc. Further, no attempt has been made to study the safety climate of Indian mfg industry, the study of safety climate of manufacturing industries strengthens the reason for the present research. This study helps the industries to implement safety standards, introduce workers involvement in safety activities that brings down accidents and injury rates at the workplace. Thus the safety climate measure is expected to help in reducing accidents and incidents creating safety awareness, industrial harmony, better safe and healthy atmosphere, identification and mitigation measures of hazards and their vulnerability and improve overall working conditions in industries. As safety is utmost important in the life of every human being, this research has been undertaken to promote safety in hazardous conditions of MHIs.

\section{Literature Review}

This section presents the results of the literature review that was conducted to understand the status of Safety Climate in the manufacturing sector of a country's economy. Although Safety Climate varies extensively based on geography and demography, the models, theories, and results from other research endeavours provide a starting point.

Cooper et al. (2004) conducted a study to determine the components of Safety Climate, in which they distributed questionnaires to employees twice, once before and once after the implementation of a behavioural safety initiative. The gap between the distributions of the questionnaires was one year. The commonly assumed link between Safety Climate and safety performance, defined as the behaviour-accident path, was not as clear as previously assumed and more research was needed to identify the nature of the relationship.

A study by Clarke et al. (2006), scrutinized conflict between production and safety, manager's concern for safety and worker's response to safety programs were important components of Safety Climate in the United Kingdom 
An analysis of Safety Climate in a large manufacturing organization in the United Kingdom by Cheyne et al. (2002) revealed the magnitude of employees' attitudes in the context of safety management and individual responsibility were crucial to explain the nuances of the model they developed. The model posited that the safety activities in an organization were mainly affected by the physical work environment and the amount of responsibility individuals were ready to assume, of which the latter was affected by communication, personal involvement and safety management. The above-said model examined the relationship between organizational components of Safety Climate such as, but not limited to, employee attitudes to organizational and individual safety issues, perceptions of [physical] work environment and self-reported Safety Climate.

These findings were similar to a model developed by Cheyne et al (1998), in which the strength of employees' attitudes with regard to safety management played an important role. In both the studies, the researchers resorted to questionnaires to measure the level of Safety Climate in the organization.

Huang et al. (2006) sampled employees from various organizations which included the manufacturing sector of United States of America. They found management commitment; return-to-work policies, post-injury administration and safety training were predominant dimensions of Safety Climate and resulted in increased safety awareness amongst workers.

Johnson (2007) conducted a study in a heavy manufacturing firm and collected the perceptions of 292 employees to unravel the predictive validity of Safety Climate questionnaire developed by Zohar and Luria (2005). Johnson found the number of components in the questionnaire could be reduced from sixteen to eleven without significant loss in accuracy of the instrument. The components that were found to be significant after exploratory factor analysis were: Safety Caring, Safety Compliance, and Safety Coaching.

The finalized safety climate components of this research can be used for the manufacturing sector by considering the local conditions. The said components are validated by considering Eigen values and weightings.

\section{Methodology}

\subsection{Questionnaire Design}

To measure Safety Climate in the manufacturing industries in Karnataka, a modified version of the questionnaire used by Hall (2013) was used. This questionnaire was selected because initially, the instrument used by Hall (2013) served as a reference. The said instrument contained 65 items. The only limitation of the original measuring instrument is that the organization's whose safety climate is measured using the instrument must have a similar work environment and organizational structure as the steel mills that were used to validate the original instrument. This need was met by the organizations chosen for the current study. After consulting experts in the field of safety in manufacturing organizations, the number of items in the questionnaire was increased to 81 and the number of components was increased from 6 to 20. Internal consistency was used to judge the quality of the measuring instrument, as advised by Cooper et al (1998). 


\subsection{Estimation of Sample Sizes}

A convenience sampling strategy was used in this study, the 13 manufacturing industries considered, 7 were from the automobile sector, 2 were from the paper manufacturing sector and 4 were from the steel manufacturing sector. The questionnaire was administered to 450 employees. After the required data pre-processing, the number of usable observations was reduced to 416 , which indicates a response rate of $92.4 \%$. Some negative questions were used to identify acquiescence bias. Even though the initial questionnaire was designed using the order of the components which appear based on frequency, the questions in the final questionnaire were shuffled to avoid a question order bias. The profile of surveyed manufacturing industries is given in Table 1.

Table 1. Demographics of Study Sample

\begin{tabular}{|c|c|c|c|}
\hline Demographic Variable & Levels & Number of Respondents & Percentage \\
\hline \multirow{2}{*}{ Gender } & Male & 408 & 98.07 \\
\hline & Female & 8 & 1.93 \\
\hline \multirow{3}{*}{ Age } & 18 to 25 years & 69 & 16.58 \\
\hline & 26 to 40 years & 204 & 49.03 \\
\hline & Above 40 years & 143 & 34.37 \\
\hline \multirow{3}{*}{ Experience } & 1 to 5 years & 93 & 22.35 \\
\hline & 6 to 15 years & 169 & 40.62 \\
\hline & More than 15 years & 154 & 37.01 \\
\hline \multirow{6}{*}{ Education } & Post Graduate & 60 & 14.42 \\
\hline & Graduate & 91 & 21.87 \\
\hline & Undergraduate & 9 & 2.16 \\
\hline & Diploma & 59 & 14.18 \\
\hline & ITI & 171 & 41.1 \\
\hline & Others & 26 & 6.25 \\
\hline \multirow{2}{*}{ Nature of job } & Technical & 371 & 89.18 \\
\hline & Non - Technical & 45 & 10.81 \\
\hline \multirow{3}{*}{ Designation } & Worker & 275 & 66.1 \\
\hline & Supervisor / Manager & 124 & 29.8 \\
\hline & CEO & 17 & 4.08 \\
\hline \multirow{4}{*}{ Department } & Production & 252 & 60.57 \\
\hline & Maintenance & 64 & 15.38 \\
\hline & Safety & 50 & 12.01 \\
\hline & Others & 50 & 12.01 \\
\hline
\end{tabular}


Description

It is evident that the distributions of respondents across some demographic variables were highly skewed. There were 408 male respondents and 8 female respondents. Approximately $50 \%$ of the respondents were between 25 and 40 years old. $40 \%$ of the respondents had between 6 and 15 years of experience. The distribution of respondents across education levels was even relative to the other demographic variables. Approximately $90 \%$ of the respondents held jobs that required technical skill. $66 \%$ of the respondents were from the working class. $60 \%$ of the respondents were from the production departments of their respective firms.

Table 2. Factors and Corresponding Items

\begin{tabular}{|c|c|c|c|c|}
\hline Items & $\begin{array}{l}\text { Safety } \\
\text { Administration }\end{array}$ & $\begin{array}{l}\text { Organizational } \\
\text { Commitment } \\
\text { Towards Safety }\end{array}$ & $\begin{array}{c}\text { Safety } \\
\text { Priority } \\
\text { Over } \\
\text { Production }\end{array}$ & $\begin{array}{c}\text { Employee } \\
\text { Commitment } \\
\text { to Safety }\end{array}$ \\
\hline My company provides innovative techniques in promoting safety. & 0.836 & & & \\
\hline I know the do's and don'ts to be followed during emergency. & 0.821 & & & \\
\hline My company provides budget for $\mathrm{R} \& \mathrm{D}$ and innovations on safety. & 0.82 & & & \\
\hline $\begin{array}{l}\text { All Firefighting equipment are in good condition and are being } \\
\text { checked at regular interval. }\end{array}$ & 0.814 & & & \\
\hline $\begin{array}{l}\text { On-site emergency plan has been prepared and training has been } \\
\text { provided to all the workers. }\end{array}$ & 0.797 & & & \\
\hline $\begin{array}{l}\text { I know sufficient numbers of fire fighting personnel are present in } \\
\text { the factory. }\end{array}$ & 0.785 & & & \\
\hline In my company PPE's are selected and monitored by the safety dept. & 0.776 & & & \\
\hline I feel that it is important to maintain safety at all times & 0.775 & & & \\
\hline $\begin{array}{l}\text { In my company team work improves the overall performance include } \\
\text { safety. }\end{array}$ & 0.772 & & & \\
\hline I am clear about what my responsibilities are for health and safety & 0.749 & & & \\
\hline My company provides ISI marked safety equipment to the workers. & 0.749 & & & \\
\hline $\begin{array}{l}\text { I am satisfied about my social status in the company and in the } \\
\text { society }\end{array}$ & 0.73 & & & \\
\hline $\begin{array}{l}\text { My company believe in team work and takes action to promote team } \\
\text { work }\end{array}$ & 0.727 & & & \\
\hline Workers are provided sufficient safety equipment by the company & 0.725 & & & \\
\hline I use all necessary Personal protective equipment to do my job & 0.714 & & & \\
\hline $\begin{array}{l}\text { I know emergency medical management and rescue system is in } \\
\text { place to meet the emergency }\end{array}$ & 0.705 & & & \\
\hline I feel that safety programmes are important and that need to be & 0.703 & & & \\
\hline
\end{tabular}


promoted

My company provides basic needs and safety for workers

I have been trained adequately to respond to emergency situations in my workplace

I feel that efforts are necessary to the incidents at workplace

0.691

Many workers in the factory are provided First aid training, fire fighting and their names have been displayed in the factory.

I know how to reduce the risk of accidents and incidents in the workplace

Regular on-site emergency mock drills are conducted in the factory.

My company pays wages better than the other companies of same status

Contract workers are provided sufficient safety training and orientation of potential hazards.

This is a safer place to work than other companies I have worked for

I know what are the hazards associated with my job.

Management provides safety training facility whenever the job/process changes and new process is introduced.

Management provided accidental insurance policy, public liability insurance in the factory.

My supervisors and managers always try to enforce safe working procedures

Management encourages the leadership and provides necessary requirements

Safety is given high antecedence by the management in my company.

Supervisors and managers encourage the workers to attend training programmes on safety

We have a effective safety leadership in my company

Management always welcomes opinion from employees before making final decisions on safety related matters

Management prepared safety and health policy of the company and circulated to all the workers

Managers and supervisors express concern if safety procedures are not adhered to

I know the occupational hazards associated in my work

Employee involvement in safety related matters are promoted by the management

My company conducts public awareness program to create 
awareness about the potential hazardous and the remedial measures

I know the budget allocated in my company for corporate social responsibility

Safety checks, pep talks and safety meetings are useful to prevent accidents and dangerous occurrences.

0.866

I feel that corrective action is always taken when management is told about unsafe practices

Management do not think safety department is a non-productive department

Management does not prioritize production by compromising safety, PPE's and tools.

My workplace is filled with inherent dangers

I have not come noticed any Occupational diseases in my factory.

In my organization employees are rewarded for informing safety hazards (thanked, cash or other rewards, recognition in news letter, 0.66 etc.)

I feel that management is not willing to compromise on safety for increasing production.

Some health and safety rules and procedures are not really practical

I follow correct safety rules and procedures while carrying out my job

I voluntarily carryout tasks or activities that help to improve workplace safety

I travel the extra mile to improve workplace safety

I am strongly encouraged to report unsafe conditions

New recruits are trained and orientated adequately so that they learn safety rules and procedures.

\section{Description}

The table gives the distribution of items across the four components identified in factor analysis. Only items with a standardized component loading greater than or equal to absolute 0.5 were considered. Safety administration contains 28 items, organizational commitment to safety has 13 items, safety priority over production has 9 components and employee commitment to safety has 5 components. Total variance explained by the four components is $47.9 \%$.

\subsection{Data Analysis}

The collected data were subjected to statistical analyses using R version 3.4.3. Exploratory factor analysis was used to determine the final distribution of items amongst the components, 
while Chi-Square tests were conducted to determine the associations between Safety Climate and the demographic variables. Parallel analysis was run to determine the number of factors that best explained the variation in the data, and the components were extracted using Principal Axis Factor. Partial Least Squares regression was used to determine the relationship the constructs shared with Safety Climate. The 'plspm' package was used run the regression analysis on the data. The results of the data analyses are discussed in the next section.

\section{Results}

\subsection{Components}

The number of components to be retained after factor analysis of a particular dataset usually determined based on the Eigen value, and this procedure seems to be the norm among researchers and software packages (Costello et al., 2005). Retention of factors based on Eigen value uses an Eigen value of 1.0 as a cut-off point, but, there is an agreement in the literature that this method has a low accuracy (Velicer et al., 1990). Alternate methods include the screen test, Velicer's MAP criteria and parallel analysis, of which the latter two are accurate and easy to use (Velicer et al., 1990). Thus, the parallel analysis was chosen as the method to extract the number of factors.

Parallel analysis was used to determine the number of components that best explained the variation in the data. Parallel analysis compares the variation explained by the number of factors with randomly generated data and checks if the differences in the variations observed are statistically significant. Such a procedure combines the power of statistical hypothesis testing and the domain knowledge that comes with experience to determine the factors.

A parallel analysis of the collected data revealed that a combination of four factors best explained the variation in the data. Tabachnick and Fidell (2001) recommend 0.32 as a cut-off value to retain items. But, because of the presence of a few cross loading items which were important, 0.5 was decided as the cut-off value to ensure that there were enough items under each factor to ensure factor stability. Thus, only items with standardized loadings greater than or equal to absolute 0.5 were considered. This resulted in the removal of 26 items from the questionnaire. The details of these four factors, along with the items, are provided in Tables 2 , 3 and 4.

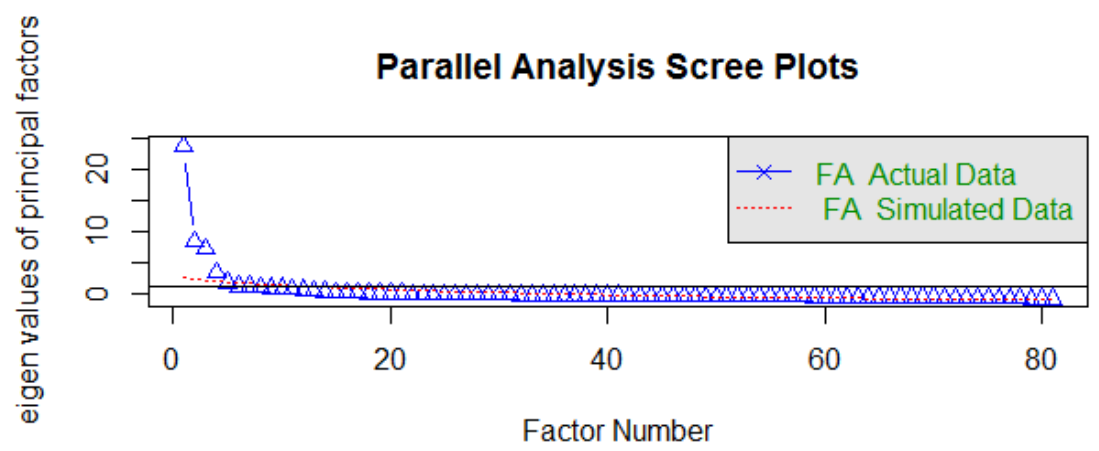

Figure 1. Parallel Analysis plot of factors. Notes. FA = Factor Analysis 
Description

Figure 1 gives the scree plot of the parallel analysis run to determine the number of factors that needed to be extracted ( 4 factors) to explain the maximum amount of variance.

Table 3. Inter-correlations among the four Safety Climate components

\begin{tabular}{cccccc}
\hline $\begin{array}{c}\text { Principal } \\
\text { Factors }\end{array}$ & $\begin{array}{c}\text { Safety } \\
\text { Administration }\end{array}$ & $\begin{array}{c}\text { Organizational } \\
\text { Commitment } \\
\text { to Safety }\end{array}$ & $\begin{array}{c}\text { Safety Priority } \\
\text { over Production }\end{array}$ & $\begin{array}{c}\text { Employees } \\
\text { Commitment } \\
\text { to Safety }\end{array}$ & $\begin{array}{c}\text { Safety } \\
\text { Climate }\end{array}$ \\
\hline $\begin{array}{c}\text { Safety Administration } \\
\text { Organizational Commitment to Safety }\end{array}$ & 1 & 0.472 & 1 & & \\
Safety Priority over Production & -0.425 & -0.27 & 1 & & \\
Employee Commitment to Safety & 0.410 & 0.519 & 0.035 & 1 & \\
Safety Climate & 0.936 & 0.736 & -0.472 & 0.567 & 1 \\
\hline
\end{tabular}

Description

Table 3 three gives the correlations between the extracted components and safety climate

\subsection{Safety Climate Measurement Model}

\subsubsection{Model Validity}

Before analysis of the data, three measurement properties need to be examined to ensure satisfactory validity and reliability of the model (Fornell et al., 1981; Mohamed, 2002). First is the individual item reliability indicated by the correlations or loadings, with 0.7 as the cut-off value. Second is the convergent validity, evaluated by Cronbach's Alpha. The cut-off value generally accepted as the threshold is 0.7 (Litwin et al., 1995), although Churchill (Churchill Jr, 1979) argues that 0.6 is also acceptable. The results in Table 2 show that the obtained Cronbach's alpha well exceeds either of the cutoffs, indicating good convergent validity. The third measurement property is discriminant validity, indicated by the average variance explained. This measure for the current model is indicated in Table 2. This should be greater than the squared inter-correlations between the elements, which are indicated in Table 3.

Since the three benchmarks have been met by the model, it can be concluded that the model measures the constructs with adequate precision.

\subsubsection{Model Assessment}

The descriptive or predictive power of any PLS model can be determined by examining the $\mathrm{R}$-squared value of the dependent constructs. R-squared indicates the amount of variation in the dependent variable that is explained by the independent variable (Sanchez, 2013). The R-squared value of 0.99 , obtained for this particular model, implies that around $99 \%$ of the variation in the safety climate was explained by the extracted components. 
Path models indicate the effect of one variable on the other. The greater is the magnitude of the path coefficient, the stronger is the effect. The figure given below, gives the path model, with standardized path coefficients, for the data. From the figure, it is seen that Safety Climate component one has a strong effect on Safety Climate, while Safety Climate components 2 and 4 have moderate effects. Safety Climate component 3 has a weak but negative relationship, i.e., it influences Safety Climate negatively. This can be verified from Table 5 .

Table 4. Model Assessment Metrics

\begin{tabular}{ccccc}
\hline Groups of Questions & $\begin{array}{c}\text { Cronbach's } \\
\text { Alpha }\end{array}$ & $\begin{array}{c}\text { Dillon-Goldstein } \\
\text { Rho }\end{array}$ & $\begin{array}{c}\text { Average Variance } \\
\text { Extracted }\end{array}$ & R-Squared \\
\hline $\begin{array}{c}\text { Safety Administration } \\
\quad \text { Organizational }\end{array}$ & 0.972 & 0.974 & 0.57 & 0 \\
$\begin{array}{c}\text { Commitment to Safety } \\
\text { Safety Priority over } \\
\quad \text { Production }\end{array}$ & 0.931 & 0.94 & 0.543 & 0 \\
$\begin{array}{c}\text { Employee Commitment to } \\
\text { Safety }\end{array}$ & 0.891 & 0.913 & 0.36 & 0 \\
$\quad$ Safety Climate & 0.952 & 0.883 & 0.593 & 0 \\
\hline
\end{tabular}

Description

Table 4 gives the assessment metrics used to validate the model. Cronbach's alpha of 0.9 indicates good convergent validity. R-squared value of 0.99 indicates that $99 \%$ of the variance in safety climate was explained by the factors.

Table 5. Path Coefficient Values from Safety Climate Components to Safety Climate

\begin{tabular}{ccccc}
\hline Variable & Estimate & Std. Error & $\mathrm{t}$ - value & $\mathrm{p}$-value \\
\hline Intercept & 0 & 0.001 & 0 & 1 \\
Safety Administration & 0.694 & 0.001 & 364 & 0 \\
Organizational Commitment to Safety & 0.318 & 0.001 & 168 & 0 \\
Safety Priority over Production & -0.098 & 0.001 & -0.565 & 0 \\
Employee Commitment to Safety & 0.121 & 0.001 & 64.2 & 0 \\
\hline
\end{tabular}

Description

Table 5 gives the metrics of the path model and describes how the extracted factors are related to safety climate. Safety administration has the greatest positive effect on safety climate, while safety priority over production has the greatest negative effect. 


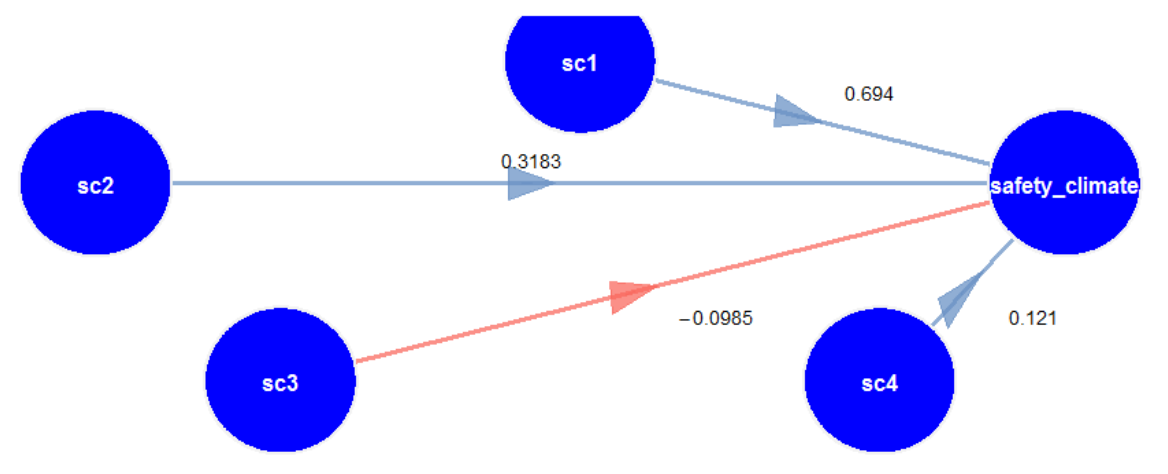

Figure 2. Path Model of PLS Regression

Description: $\mathrm{sc} 1=$ Safety Administration, $\mathrm{sc} 2=$ Organizational Commitment to Safety, $\mathrm{sc} 3=$ Safety Priority over Production, sc $4=$ Employee Commitment to Safety. The full colour version of the figure is available online.

\section{Discussion}

This paper tried to explicate the little-explored subject of Safety Climate in Indian manufacturing industries. Based on available literature and expert opinions, the components of the questionnaire were fixed. The questionnaire was distributed to 450 respondents, out of which 416 responses were perfectly usable. The data collected was then subjected to factor analysis to determine the components that best explained the variation in the data. Those components were then used to explore the relationship between Safety Climate. The statistical analysis yielded four components of Safety Climate, namely: Safety administration, Organizational commitment to safety, Safety Behaviors and Safety Commitment.

\subsection{Safety Administration}

The literature review yielded components that have been declared as important to Safety Climate. However, safety administration has not been considered as a component of Safety Climate in the Indian manufacturing sector.

Safety Administration can be defined as all activities of planning, implementation and execution for safety that include the formation of safety rules and procedures; risk assessment and justification; emergency preparedness; safety training and development; deciding on PPE; budgeting for safety; inculcation of teamwork for safety and promoting the spirit of innovation towards safety.

Clarke et al. (2006) obtained a similar component (administrative safety issues) in their study. This was determined to be a significant predictor of safety climate and explained around $28 \%$ of the variance in the data. The researchers found Safety Climate encompasses safety training/instructions, follow up measures of accidents and injuries and safety inspections.

\subsection{Organizational Commitment to Safety}


Organizational commitment to safety refers to the employee perceptions of the importance the organization places on safety in the workplace. The burgeoning research on a strong management commitment to safety reveals it is an important component that shapes and produces a positive Safety Climate in the organization (DeJoy et al., 2004; Dedobbeleer et al., 1998; Flin et al., 2000).

\subsection{Safety Priority over Production}

Safety Priority over Production is a construct that evaluates how the management of an organization views safety relative to production. This, however, is a perception of the employees. Vinodkumar and Bhasi (2009) conducted a study in chemical industries of Kerala and found that the employees of the eight major accident hazard industries felt that their respective managements placed production over safety. They retained this particular factor even though it had low-reliability scores because of the high correlations it shared with self-reported accident rates. Another reason for retention of this factor by the said authors was because of the significant association this factor shared with workers who had experienced accidents and those who hadn't experienced any.

This finding is similar to the finding of the current study, which also indicates that the employees feel that the organization's value production over safety. Even though the quoted study was conducted in a geographically different region, such a similarity might exist because the high-risk and safety-critical nature of the industries considered.

\subsection{Employee Commitment to Safety}

Vinodkumar and Bhasi (2009), found worker's participation and commitment to safety to be significantly negatively correlated with self-reported accident rates. They found that the said construct was a significant factor of safety climate.

This is a relatable finding because the current study also found employee commitment to safety to be a significant predictor $(\mathrm{p}<0.01)$ of safety climate. This is indicated by a path coefficient of 0.121 , which indicates that employee commitment to safety has a moderate effect on safety climate.

\section{Conclusion}

This paper identified factors of safety climate that significantly affect safety climate in the manufacturing industry in Karnataka. Out of the four factors identified three factors: Safety administration, organizational commitment to safety and employee commitment to safety were found to positively influence safety climate. The other factor safety priority over production negatively affected safety climate. These results reveal, to a certain extent, components that influence safety climate in the Indian manufacturing industry.

\section{Scope}

This study deals with the status of safety climate in major hazard industries in India. And as a result, the measuring instrument that is obtained can be used to measure the status of safety climate in major hazard industries in developing countries in the world. 


\section{References}

Budworth, N. (1997). The development and evaluation of a safety climate measure as a diagnostic tool in safety management. Iosh Journal, 1, 19-29.

Cheyne, A., Cox, S., Oliver, A., \& Tomás, J. M. (1998). Modelling Safety Climate in the prediction of levels of safety activity. Work \& Stress, 12(3), 255-271. https://doi.org/10.1080/02678379808256865

Churchill Jr, G. A. (1979). A paradigm for developing better measures of marketing constructs. Journal of marketing research, 64-73. https://doi.org/10.1177/002224377901600110

Clarke, S. (2006). Safety Climate in an automobile manufacturing plant: The effects of work environment, job communication and safety attitudes on accidents and unsafe behavior. Personnel Review, 35(4), 413-430. https://doi.org/10.1108/00483480610670580

Cooper, M. D., \& Phillips, R. A. (2004). Exploratory analysis of the safety climate and safety behavior relationship. Journal of safety research, 35(5), 497-512. https://doi.org/10.1016/j.jsr.2004.08.004

Cooper, R. K., \& Sawaf, A. (1998). Executive EQ: Emotional intelligence in leadership and organizations. Penguin.

Costello, A. B., \& Osborne, J. W. (2005). Best practices in exploratory factor analysis: Four recommendations for getting the most from your analysis. Practical assessment, research \& evaluation, 10(7), 1-9.

Dedobbeleer, N., \& Béland, F. (1998). Is risk perception one of the dimensions of Safety Climate. Occupational injury: Risk prevention and intervention, 73-81. https://doi.org/10.1201/9780203212493.pt3

DeJoy, D. M., Schaffer, B. S., Wilson, M. G., Vandenberg, R. J., \& Butts, M. M. (2004). Creating safer workplaces: assessing the determinants and role of Safety Climate. Journal of safety research, 35(1), 81-90. https://doi.org/10.1016/j.jsr.2003.09.018

Flin, R., Mearns, K., O'Connor, P., \& Bryden, R. (2000). Measuring Safety Climate: identifying the common features. Safety science, 34(1-3), 177-192. https://doi.org/10.1016/S0925-7535(00)00012-6

Fornell, C., \& Larcker, D. F. (1981). Evaluating structural equation models with unobservable variables and measurement error. Journal of marketing research, 39-50. https://doi.org/10.1177/002224378101800104

Hall, M. E. (2006). Measuring the safety climate of steel mini-mill workers using an instrument validated by structural equation modeling.

Hall. (2013). Journal of Safety, Health and Environmental Research, 9(1).

Huang, Y. H., Ho, M., Smith, G. S., \& Chen, P. Y. (2006). Safety climate and self-reported injury: Assessing the mediating role of employee safety control. Accident Analysis \& Prevention, 38(3), 425-433. https://doi.org/10.1016/j.aap.2005.07.002

Johnson, S. E. (2007). The predictive validity of Safety Climate. Journal of safety. 
https://doi.org/10.1016/j.jsr.2007.07.001

Litwin, M. S., \& Fink, A. (1995). How to measure survey reliability and validity (Vol. 7). Sage. https://doi.org/10.4135/9781483348957

Mohamed, S. (2002). Safety Climate in construction site environments. Journal of construction engineering and management, 128(5), 375-384. https://doi.org/10.1061/(ASCE)0733-9364(2002)128:5(375)

Oliver, A., Cheyne, A., Tomás, J. M., \& Cox, S. (2002). The effects of organizational and individual factors on occupational accidents. Journal of Occupational and Organizational psychology, 75(4), 473-488. https://doi.org/10.1348/096317902321119691

Sanchez, G. (2013). PLS path modeling with R. Berkeley: Trowchez Editions.

Velicer, W. F., \& Jackson, D. N. (1990). Component analysis versus common factor analysis: Some issues in selecting an appropriate procedure. Multivariate behavioral research, 25(1), 1-28. https://doi.org/10.1207/s15327906mbr2501_1

Vinodkumar, M. N., \& Bhasi, M. (2009). Safety climate factors and its relationship with accidents and personal attributes in the chemical industry. Safety Science, 47(5), 659-667. https://doi.org/10.1016/j.ssci.2008.09.004

Zohar, D., \& Luria, G. (2005). A multilevel model of Safety Climate: cross-level relationships between organization and group-level climates. Journal of applied psychology, 90(4), 616. https://doi.org/10.1037/0021-9010.90.4.616

\section{Copyright Disclaimer}

Copyright for this article is retained by the author(s), with first publication rights granted to the journal.

This is an open-access article distributed under the terms and conditions of the Creative Commons Attribution license (http://creativecommons.org/licenses/by/4.0/) 